\section{Infección respiratoria por Sphingobacterium multivorum}

\section{Sr. Director:}

Describimos un caso de infección respiratoria causada por Sphingobacterium multivorum, en un paciente afectado de obstrucción crónica al flujo aéreo, en el que ni los datos clínicos ni analíticos sugerían la presencia de inmunodepresión sistémica.

El caso en cuestión es un paciente de 74 años de edad, previamente diagnosticado de enfermedad pulmonar obstructiva crónica con insuficiencia respiratoria crónica, y que contaba con varios ingresos hospitalarios anteriores debidos a infecciones bronquiales por Pseudomonas sp. Al ser atendido nuevamente en la consulta de Neumología, el paciente refiere que en los últimos 4 días viene padeciendo escalofríos, sudor, fiebre y tos con expectoración purulenta, todo ello acompañado de sibilancias y disnea progresiva hasta hacerse de reposo, así como dolor en hemitórax derecho cuando tose. Al examen clínico el paciente se muestra orientado y colaborador, presentando taquipnea sin cianosis y una temperatura de $38^{\circ} \mathrm{C}$, y los datos analíticos revelan una velocidad de sedimentación globular de $58 \mathrm{~mm}$ en la primera hora, neutrofilia del $91,3 \%$, y presión arterial de oxígeno de 49 $\mathrm{mm}$ de $\mathrm{Hg}$.

Sphingobacterium multivorum no es un patógeno frecuente, pues se trata de una bacteria saprofita que puede encontrarse en los suelos habiéndose demostrado la transferencia de plásmidos a partir de bacterias nitrificantes, y que también se aíslan a partir de abonos de origen ovino (1). Se trata de bacilos gram-negativos, pequeños y pleomórficos con contienen esfingolípidos (2), próximos filogenéticamente a las especies del género Flavobacterium, con el que constituyen el complejo Flavobacterium-CytophagaSphingobacterium, caracterizado por presentar a la homoespermidina como marcador quimiotaxonómico común. Otros géneros que se incluyen junto a Sphingobacterium en la superfamilia V rRNA son Flexibacter, Weeksella, Cytophaga y Moraxella anati pestifer (3), si bien el género actualmente considerado más próximo a Sphingobacterium es Pedobacter, con quien constituiría una rama separada de la superfamilia citada: la familia Sphingo bacteriaceae. Algunas bacterias filogenéticamente relacionadas con especies del género Sphingobacterium, se han hallado asociadas a la myxobacteria Chondromyces crocatus $(2,4)$. Por otra parte, algunas especies del género Sphingobacterium, lo mismo que otras especies de bacterias aisladas del compost, son capaces de transformar los ácidos grasos insaturados produciendo, en el caso del ácido oleico, 10-hidroxiesteárico y cetoesteárico (5).

En 1987 se publicó un primer caso de Sphingobacterium mul tivorum aislado a partir de un hemocultivo procedente de un paciente que estaba recibiendo tratamiento quimioterápico para el linfoma que padecía (6), y que respondió bien al tratamiento antibiótico superando la infección. Posteriormente, se ha descrito también el aislamiento de esta misma especie bacteriana en un paciente afectado de fibrosis quística (7), caso que presenta gran analogía con nuestro hallazgo, puesto que ambos pacientes adolecen de la suficiente capacidad inmunitaria en el territorio pulmonar, si bien por mecanismos diferentes, y aún cuando no puedan ser considerados como inmunodeprimidos desde un punto de vista global; de hecho nuestro paciente había estado previamente infectado por Pseudomonas, una de las bacterias que con más frecuencia se aíslan en los esputos de pacientes afectados de fibrosis quística. Por otra parte, el aislamiento de Sphingobacterium multivorum en pacientes con la inmunidad deprimida tampoco es un hecho frecuente, habiéndose cifrado en cinco los casos descritos hasta 1996, fecha en la que se comunicó un caso de septicemia en un paciente de 47 años de edad portador del virus de la inmunodeficiencia humana, que presentaba historia de fiebre, escalofríos y pérdida de peso durante los 3 tres meses precedentes, y del que se consiguió aislar el germen a partir de muestras de sangre y de esputos (8).

La cepa aislada en nuestro laboratorio resultó resistente in vitro a ceftazidima y aztreonam, y presentó una sensibilidad intermedia a tobramicina y ticarcilina, en tanto que fue sensible a otros betalactámicos y aminoglucósidos, así como a tetraciclina, sulfamidas y a varias quinolonas. Se han descrito algunas cepas nosocomiales de Sphingobacterium multivorum resistentes tanto a ceftazidima como a imipenem $(9,10)$, capaces de inactivar por hidrólisis a este último betalactámico; también se ha descrito alguna cepa sensible a ceftazidima (8). En nuestro caso, la cepa resultó in vitro sensible a imipenem, y resistente a ceftazidima, si bien la eficacia de imipenem in vivo habría que considerarla con cautela teniendo en cuenta la capacidad de diversas cepas de Sphingobacterium multivorum para inactivar por hidrólisis dicho betalactámico.

Antes de disponer de los resultados microbiológicos y dado su historial repetido de infecciones por Pseudomonas, se inició tratamiento con ceftazidima, sustituido por una de las cefalosporinas a las que resultó sensible (cefuroxima, vía oral) en cuanto se dispuso de los resultados del cultivo microbiológico, lo que con- 
dujo a la curación completa, eliminándose los síntomas clínicos y obteniéndose sucesivos cultivos negativos. Consideramos interesante la comunicación de hallazgos de este tipo, con objeto de no infravalorar la incidencia de infecciones causadas por bacterias en principio poco frecuentes, y que habitualmente no son capaces de producir infecciones sino en sujetos inmunodeprimidos.

\section{J. C. Vella Ramírez, A. Simón Rodríguez*}

Servicio de Análisis Clínicos. *Servicio de Neumología. Hospital Divino Valles. Junta de Castilla y León. Burgos

1. Chikh G, Pourquie J, Kaiser P, Davila AM. Characterization of the bacterial flora isolated from a pilot-scale lagoon processing swine manure. Can J Microbiol 1997; 43: 1079-83.

2. Jacobi CA, Reichenbach H, Tindall BJ, Stackebrandt E. "Candidatus comitans", a bacterium living in coculture with Chondromyces crocatus (myxobacteria). Int J Syst Bacteriol 1996; 46: 119-22.

3. Segers P, Mannheim W, Vancanneyt M, et al. Riemerella anatipestifer gen.nov., comb.nov., the causative agent of septicemia anserum exsudativa, and its phylogenetic affiliation within the Flavobacterium-Cytophaga rRNA homology group. Int J Syst Bacyteriol 1993; 43: 768-76.

4. Jacobi CA, Assmus B, Reichenbach H, Stackebrandt E. Molecular evidence for association between the sphingobacterium-like organism "Candidatus comitans" and the myxobacterium Chondromyces crocatus. Appl Environ Microbiol 1997; 63: 719-23.

5. Kaneshiro T, Kuo TM, Nakamura LK. Conversion of unsaturated fatty acids bacteria isolated from compost. Curr Microbiol 1999; 38: 250-5.

6. Freney J, Hansen W, Ploton C, et al. Septicemia caused by Sphingobacterium multivorum. J Clin Microbiol 1987; 25: 1126-8.

7. Reina J, Borrell N, Figuerola J. Sphingobacterium multivorum isolated from a patient with cystic fibrosis. Eur J Clin Microbiol Infect Dis 1992; 11: 81-2.

8. Areekul S, Vongsthongsri U, Mookto T, Chettanadee S, Wilairatana P. Sphingobacterium multivorum septicemia: a case report. J Med Assoc Thai 1996; 79: 385-98.

9. Blahova J, Kralikova K, Krcmery VSr, Kubonova K. Hydrolysis of imipenem, meropenem, ceftazidime, and cefepime by multiresistant nosocomial strains of Sphingobacterium multivorum. Eur J Clin Microbiol Infect Dis 1997; 16: 178-80.

10. Blahova J, Hupkova-Lesicka M, Kralikova K, Krcmery VSr, Kubonova $\mathrm{K}$. The effect of cefepime on ceftazidime, cefotaxime and imipenem resistant strains of Acinetobacter, Xanthomonas, Pseudomonas, Flavobacterium. Sphingobacterium and on producers of extended spectrum beta-lactamases (ESBL) with resistance transfer. Cas Lek Cesk 1997; 136: $154-6$. 